Ökonomie contra Ökologie? 


\section{Ökonomie contra Ökologie?}

Wirtschaftsethische Beiträge zu Umweltfragen

herausgegeben von

Prof. Dr. Sigurd Martin Daecke RWTH Aachen 
Deutsche Bibliothek - CIP-Einheitsaufnahme

Ökonomie contra Ökologie? : Wirtschaftsethische Beiträge

zu Umweltfragen / hrsg. von Sigurd Martin Daecke. -

Stuttgart ; Weimar : Metzler, 1995

ISBN 978-3-476-01369-9

NE: Daecke, Sigurd Martin [Hrsg.]

ISBN 978-3-476-01369-9

ISBN 978-3-476-03629-2 (eBook)

DOI 10.1007/978-3-476-03629-2

Dieses Werk einschließlich aller seiner Teile ist urheberrechtlich geschützt. Jede Verwertung außerhalb der engen Grenzen des Urheberrechtsgesetzes ist ohne $\mathrm{Zu}$ stimmung des Verlages unzulässig und strafbar. Das gilt insbesondere für Vervielfältigungen, Übersetzungen, Mikroverfilmungen und die Einspeicherung und Verarbeitung in elektronischen Systemen.

(C) 1995 Springer-Verlag GmbH Deutschland

Ursprünglich erschienen bei J. B. Metzlersche Verlagsbuchhandlung

und Carl Ernst Poeschel Verlag GmbH in Stuttgart 1995 


\section{Inhalt}

Einleitung

Sigurd Martin Daecke

Umweltethik als wirtschaftsethische Aufgabe

Philosophisch-theologische Anmerkungen zum Verhältnis von

Ökonomie und Ökologie

Karl Georg Zinn

Wie umweltverträglich sind unsere Bedürfnisse?

$\mathrm{Zu}$ den anthropologischen Grundlagen von Wirtschaftswachstum und Umweltzerstörung

Hans-Jürgen Zimmermann

,Unscharfer Wirtschaftsethik

Kontext und Wortbedeutung in der ethischen Diskussion

\section{Ulrich Brösse}

Ökonomisches Verhalten als bester Weg zu einer nachhaltigen Umweltverbesserung

\section{Werner Gocht}

Umwelt und Entwicklung:

Armut als Ursache für Umweltschäden

Cornelia Zanger

Ökologie versus Ökonomie -

ein Widerspruch besonders in den neuen Bundesländern?

\section{Harald Dyckhoff}

Umweltschutz - ein Thema für die Betriebswirtschaftslehre? 108

\section{Heribert Meffert/Manfred Kirchgeorg}

Marktorientiertes Umweltmanagement -

eine wettbewerbsstrategische Perspektive 


\section{Hans-Horst Schröder}

Umwelt(schutz)orientiertes Rechnungswesen

Steuerungsinstrument zur Bewältigung der Umweltprobleme oder Public-Relations-Instrument?

\section{Klaus Henning}

Kybernetische Modellbildung für offene komplexe Systeme

am Beispiel der Reduzierung von energiebedingten

$\mathrm{CO}_{2}$-Emissionen

Verzeichnis der Autoren 